日本におけるCOVID-19による大学生の歩数の減少

ースマートフォンアプリケーションによる調查一

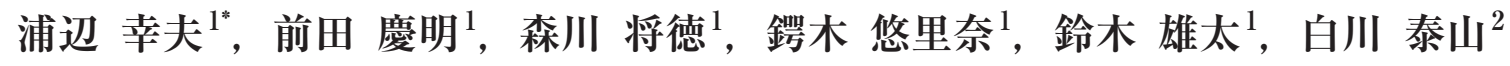

\title{
Decreasing for walking steps with collegiate students during COVID-19 pandemic in Japan -A survey based on smartphone application-
}

\author{
Yukio Urabe $^{{ }^{*}}$, Noriaki Maeda ${ }^{1}$, Masanori Morikawa ${ }^{1}$, Yurina Tsubaki ${ }^{1}$, \\ Yuta Suzuki ${ }^{1}$ and Taizan Shirakawa ${ }^{2}$ \\ ${ }^{1}$ 広島大学大学院医系科学研究科, =734-8553 広島県広島市南区霞 1-2-3 (Graduate School of Biomedical and Health Sci- \\ ence, Hiroshima University, 1-2-3 Kasumi, Minami-ku, Hiroshima, Hiroshima 734-8553, Japan) \\ 2マッターホルンリハビリテーション病院， テ737-0046 広島県点市中通1-5-25 (Matterhorn Rehabilitation Hospital, 1-5- \\ 25 Nakadori, Kure, Hiroshima 737-0046, Japan)
}

Received: June 26, 2020 / Accepted: January 12, 2021

\begin{abstract}
Novel coronavirus disease (COVID-19) spread worldwide. In Japan, From April 16 to May 25, 2020, a state of emergency was declared and people were "strongly requested to refrain from going out unnecessarily and thoroughly reduce contact with others." As a result, the number of steps of all generations was expected to be lower than usual due to the novel coronavirus disease pandemic. This study investigated the weather walking steps decrease in the collegiate student due to COVID-19. A total of 221 collegiate students used their smartphones to enter the average number of steps taken every month from January to May. The number of steps taken by all students was 4,988 $\pm 2,345$ steps in January, 5182 $\pm 2,516$ steps in February, 5,118 $\pm 2,291$ steps in March, 3,281 $\pm 1,689$ steps in April, and 2,834 $\pm 1,676$ steps in May. A comparison between sex groups showed that the number of steps in April and May was significantly different $(p<0.05)$, which means that the steps of women group was lower than that of men. These results suggest that the number of steps taken by students decreased with the outbreak of the novel coronavirus disease.
\end{abstract}

Jpn J Phys Fitness Sports Med, 70(2): 175-179 (2021)

Keywords : COVID-19 infection, walking steps, collegiate student, health promotion, behavior modification

緒言

2019年 12 月末に中国湖北省武漢で最初の新型コロナ ウイルス感染症（coronavirus disease 2019: COVID-19） が確認された ${ }^{1)}$ 。感染症は，またたく間に世界に拡散し， 多くの感染者と死者がでた. 我が国でも2020年 3 月頃か ら感染者や死亡者が増加し始めた ${ }^{2)}$. その結果, 世界規 模での人の移動が遮断され, 各国で屋外活動が制限され た。我が国では，4月中旬から約 1 か月にわたり，全国 に緊急事態宣言が実施された ${ }^{3)}$ 。この緊急事態宣言の期 間中は, 政府から stay homeで不要不急の外出を自肃す ることや，県をまたぐような移動（旅行）の制限が指示 された。

*Correspondence: yurabe@hiroshima-u.ac.jp
このような背景から, COVID-19の感染予防のために 身体活動が低下することが危惧されている ${ }^{4)}$ 。実際， ス マートフォンのアプリケーションを用いた調査において も，日本人の歩数が緊急事態宣言中に大きく減少してい ることが報告されている5)。これによって今後の疾病の 発生率が変化することや, 国民の健康状態に悪影響が出 ることが懸念される。実際, 歩行はnon-communicable diseases（NCDs）のリスクを軽減させ，健康増進を促進 するための効果的な身体活動の一つでもあるとされてい $ろ^{6,7)}$

筆者らはこれまでに大規模災害での歩数の減少や ${ }^{8)}$, 大学生の身体活動不足を表す指標として歩数の調査を 行ってきた . 特に大学生を対象にした研究では, 日本 の同年代の平均歩数と比べて, 広島地区の大学生の歩数 が小さかったことを示した。また，COVID-19により教 
育施設も対応を求められ，オンライン授業に移行する措 置をとったことから, 大学生のさらなる身体活動の低下 につながっている可能性がある.

そこで本研究では, 広島市の大学生を中心にCOVID-19の流行前後の期間中の歩 (行) 数の変化を調查し, COVID-19の影響により歩数がどの程度減少したのかを 明らかにすることを目的とした。

\section{方法}

対象者 対象は, $\mathrm{H}$ 大学の医学部, 歯学部, 薬学部の学 部生（在籍人数は約 400 名）である. Google フォームを 通じて研究の趣旨に賛同の得られた者をリクルートし， 回答を以って同意とみなした。なお，本研究は広島大学 疫学倫理審査委員会の承認を得て実施した（E-2109）。

歩数の調査 対象のスマートフォンから $1 \sim 5$ 月の毎月 の平均歩数を調查した，iOS端末を使用している対象は 「ヘルスケア」(Apple inc.) というアプリケーションから, Android端末を使用している対象は「Google fit」(Google LLC.) というアプリケーションからそれぞれ歩数を抽出 した。iOS端末とAndroid端末で歩数調査を行うことの 妥当性については既に検討されている ${ }^{10,11)}$ 。他に，身体 の基本デー夕 (性別, 年齢, 身長, 体重)を聴取した。

なお，我が国では政府から 2020 年 4 月 15 日から 5 月 25日にかけて，全国47都道府県に対して，「stay home で外出を自肃するように」「都道府県をまたいだ移動禁 止の遵守」を呼びかける「緊急事態宣言」が出された.

歩数の調査は 2020 年 6 月 1 ～15日の間で行われた。調 査に協力してくれた対象は，いずれもこのような調査を することを事前に知らされていなかった.

統計分析 時間（1月， 2 月， 3 月， 4 月， 5 月）による歩 数の違いを調查するために男女混合の反復測定一元配置 分散を実施した，有意であれば，事後検定としてBonferroni 法による多重比較を実施した。時間 ( 1 月, 2 月, 3 月, 4 月，5月）と性別（男性, 女性）による二要因による歩 数の違いを検討するために，二元配置分析（対応あり $\times$ 対応なし）を実施した。主効果のみ認められた場合, 時
間についてはBonferroni法による多重比較を実施した。 性別については対応のない $\mathrm{t}$ 検定を実施した。交互作用 が見られた場合は，Bonferroni法による多重比較を実施 した。危険率 $5 \%$ 未満を統計的有意とした。統計学的解 析には, SPSS 25.0（IBM Corporation, NY, USA）を用 いた。

\section{結果}

221名（男性143名, 女性78名）のデー夕が得られた。 全体の年齢は $20.7 \pm 3.7$ 歳, 身長は $166.5 \pm 8.4 \mathrm{~cm}$, 体重は $60.4 \pm 11.7 \mathrm{~kg}$, BMI $21.7 \pm 3.2 \mathrm{~kg} / \mathrm{m}^{2}$ であった。男性 の年齢は $20.9 \pm 3.6$ 歳，身長は $170.9 \pm 6.4 \mathrm{~cm}$ ，体重は64.7 $\pm 10.4 \mathrm{~kg}, \mathrm{BMI} は 22.1 \pm 2.9 \mathrm{~kg} / \mathrm{m}^{2}$ であった，女性の年 齢は $20.3 \pm 3.8$ 歳，身長は $158.5 \pm 5.1 \mathrm{~cm}$, 体重は $52.5 \pm 9.7$ kg，BMIは20.9 $3.5 \mathrm{~kg} / \mathrm{m}^{2}$ であった。

Table 1 に月毎の歩数の平均值と全体の歩数の月ごと の比較を示す. 221 名の大学生は, 2020年 1～3 月までの 3 か月間は全体の平均歩数が 5,000 歩程度で一定だった。 4 月は 3,281 歩に減少した $(\mathrm{p}<0.01)$ 。これは, 1 ～ 3 月 の約 $64 \%$ 程度の歩数であった. 5 月平均歩数は 2,843 歩 と最低になった。これは 1 〜 月の約 $56 \%$ 程度の歩数で あった. Fig. 1に男女別の月毎の歩数の変化を示す.二 元配置分散分析の結果，時間と性別に交互作用を認めた $(\mathrm{d}=1, \mathrm{~F}=3.147, \mathrm{p}<0.014)$. 多重比較の結果，女性の歩 数は 4 5 月では男性より少なかった $(\mathrm{p}<0.05)$.

\section{考察}

本研究では, COVID-19の感染被害がひろがった2020 年 1 月から現時点（5月）まで, 大学生がどの程度の歩 数を示しているかを明らかにできた。また，本研究では 対象には事前に調査を行うことが伝えられておららず，対 象の提示した歩数については意図のないものであると考 えられる

2020 年 4 月と 5 月に大学生の歩数が 1 〜 月の 56 $64 \%$ となったことは，本研究で最も特筆すべき結果で ある。4月中ばから我が国で「緊急事態宣言」が出さ れ，日常的な社会活動の自肃を余儀なくされ，日本国民 はstay homeや場合によっては「巣ごもり」という状態

Table 1. Mean walking steps and their comparions

\begin{tabular}{lcccll}
\hline & Overall $(\mathrm{n}=221)$ & Men $(\mathrm{n}=143)$ & Women $(\mathrm{n}=78)$ & $\mathrm{p}$ \\
\cline { 2 - 5 } January & $4988 \pm 2345$ & $5178 \pm 2314$ & $4641 \pm 2378$ & $*$ (vs April, May) \\
February & $5182 \pm 2516$ & $5172 \pm 2414$ & $5199 \pm 2710$ & $*$ (vs April, May) \\
March & $5118 \pm 2291$ & $5250 \pm 2467$ & $4874 \pm 1918$ & $*$ (vs April, May) \\
April & $3281 \pm 1689$ & $3509 \pm 1743$ & $2863 \pm 1508$ & $*$ (vs January, February, March, May) \\
May & $2834 \pm 1676$ & $3074 \pm 1659$ & $2393 \pm 1626$ & $*$ (vs January, February, March, April) \\
\hline
\end{tabular}

*: indicated the significant difference $(\mathrm{p}<0.05)$ among months in the overall $(\mathrm{n}=221)$ mean step count. 


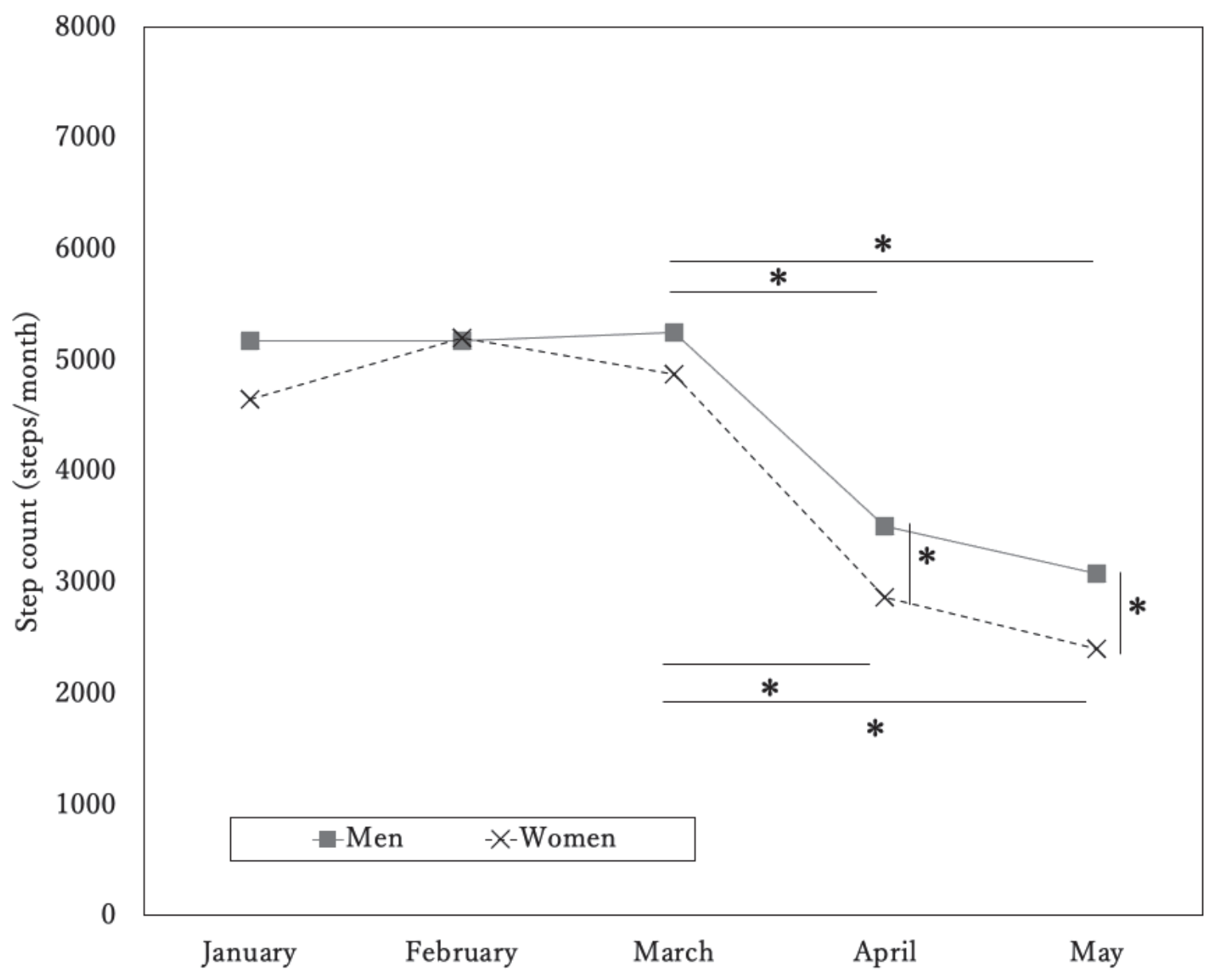

Fig. 1 Change of mean walking steps in both genders between January to May. The mean walking steps decreased from April. Especially, women were less the walking steps than men in April and May. $*$ : $p<0.05$

で，外出を極端に控えていた可能性もある，実際，COVID-19により大学生の身体活動量が低下したというイ タリアの報告もある ${ }^{12)}$. そのため, 本研究で日本人大学 生でも客観的な指標をもってその実情が明らかにできた ことは意味がある。毎日3,000歩から，多く見積もって も4,000歩しか歩いていないことは, 日本人の目標歩数 から考えて相当な身体活動不足の状態にあることを示し ている．今回COVID-19に関連した自肃生活によって身 体活動量の低下状態にあったことが，今後持続する生涯 の生活に影響するのか否か, 大変興味のもたれるところ である、筆者らの調査 ${ }^{9)}$ では, 健康教育の中でウォーキ ングの重要性を説けば，歩数が一時的に向上することは 確かめられているが，教育期間が終了した後に向上した 歩数が維持できているのはごく少数であった，それだけ， 歩行を健康運動として身につけるという行動変容は, 大 変困難であると言わざるを得ない，今後注意媣く観察を 続けていき, 2020 年 6 月以降に大学生の歩数が増加する ことに期待したい.

女性の歩数が男性より少なかった。これは多くの論文
で示されている結果でもある ${ }^{13)}$. 歩行をはじめとする身 体活動は骨粗鬆症と関連があるが14)，我が国の女性は長 命ではあり将来骨粗鬆症を罹患する可能性が高く, 歩行 を通じて骨粗しょう症を予防することも必要である，女 性の外出機会や身体活動の機会を増加させる魅力的な企 画を提供することが必要である.

この 10 年間でみると, 男性では有意な増減はないが, 女性では有意に減少している ${ }^{15)}$ ，健康日本21 (二次) で は, 2022年までに64歳までの成人男性 9,000歩, 女性8,500 歩にするという目標を2013年にたてている ${ }^{16)}$. 特に 20 代女性の歩数が全体の年齢層のなかでピークに近い.こ のような状況下で, 本研究により緊急事態宣言中の大学 生の歩数が大きく減少したことは深刻的であり, 運動 により健康を維持するための国民の行動変容（behavior modification）が求められる.

筆者らは東日本大震災という未曾有の災害を経験し, そこでも災害復興住宅に避難した人々が身体活動不足に 陥ったケースを観察してきた ${ }^{8)}$ 。避難者の歩数は男性で $4,716 \pm 3,230$ 歩, 女性で $4,165 \pm 2,805$ 歩であったが, 今回 
得られた緊急事態宣言期間中の $4 \sim 5$ 月の歩数の方が小 さい值であった，災害から 1.5 年経過した後でも，立位保 持バランス能力が低下したままであったことも報告され ている ${ }^{17)}$ ，今回のCOVID-19の感染症の拡大も災害に似 たところがある。対象が高齢者であったことに注意を要 するが，本研究で得られた一時的な歩数の低下が，今後 の立位バランスに影響する可能性がある。東日本大震災 で得た多くの教訓を, 今回のCOVID-19の対応に役立て ることも必要であると考えられる。

本研究の限界として対象が広島県在住の大学生のみで あることがあげられる，全国の各地域で同様のこと以外 の事実が発生している可能性がある。また，対象が医学 部であり, 健康問題に関する知識を有する学生であった ことが歩数に影響した可能性がある。加えて, 本研究の 対象には極端に歩数の低いものがいた。これは, 緊急事 態宣言でのstay home中に, 自宅内ではスマートフォン を身につけずにいたため, 歩数のカウントがされなかっ たということが確認されている。これにより，今回示 した歩数より，実際の歩数は多いことが想像されるが, stay homeで自宅からほとんど外出をしなかったという 現実を表している数值とも考えられる。また，スマート フォンでは寝室や居間から台所やトイレまでの比較的近 距離で歩数が少なく，歩行速度が低いような時には，身 体に身につけていても歩数がカウントされないことも多 い.しかし，これらの欠点があるにせよ，スマートフォ ンアプリを使用する意義は大きいと考える。スマート フォンのウォーキングアプリデータを利用した調査は, 記録が残っている期間であれば実施が可能であるため, 今後大規模な調査を実施することで同様の変化が認めら れるかを検討することが求められる.

\section{結 語}

COVID-19後に，スマートフォンのウォーキングアプ リを使用して，大学生の歩行数を確認した結果，国民の 目標値を大きく下回っていた，緊急事態宣言が出された 2020年 4 月から 5 月にかけて, 外出自肃の結果, 極端に 歩数が減少した。期間を通じて女性の歩数が男性より少 なかった，今後，COVID-19の影響により低下した歩数 を回復させ，また将来的な健康の保持・増進を考える上 でも以前の歩数以上になるための対策を構築していくこ とが重要である。

\section{利益相反自己申告 :}

本研究では，開示すべきCOI関係にある企業などはない

\section{著者貢献}

UY, 研究の概念化, 研究計画の立案, デー夕収集, 論文原 稿の執筆，研究論文の発表に関する最終的な承認
$\mathrm{MN}$, 研究の概念化

$\mathrm{MM}$, 論文原稿の執筆，デー夕収集

TY, 論文原稿の執筆，デー夕収集

$\mathrm{SY}$, 論文原稿の執筆, デー夕収集

ST, 研究の概念化

\section{文献}

1) Huang C, Wang Y, Li X, Ren L, Zhao J, Hu Y, Zhang L, Fan G, Xu J, Gu X, Cheng Z, Yu T, Xia J, Wei Y, Wu W, Xie X, Yin W, Li H, Liu M, Xiao Y, Gao H, Guo L, Xie J, Wang G, Jiang R, Gao Z, Jin Q, Wang J, Cao B. Clinical features of patients infected with 2019 novel coronavirus in Wuhan, China. Lancet 395: 497-506, 2020. doi: 10.1016/S0140-6736 (20) 30183-5.

2）厚生労働省. 新型コロナウイルス感染症の国内発生動 向, 2020. https://www.mhlw.go.jp/content/000651999. pdf（アクセス日：2020年 9 月 18日).

3）厚生労働省. 新型コロナウイルス感染症対策の基 本的対処方針, 2020. https://www.mhlw.go.jp/content/10900000/000633503.pdf（アクセス日：2020年 9 月 18 日).

4) Lippi G, Henry BM, Sanchis-Gomar F. Physical inactivity and cardiovascular disease at the time of coronavirus disease 2019 (COVID-19). Eur J Prev Cardiol 27: 906-908, 2020. doi: 10.1177/2047487320916823.

5) Tison GH, Avram R, Kuhar P, Abreau S, Marcus GM, Pletcher MJ, Olgin JE. Worldwide effect of COVID-19 on physical activity: A descriptive study. Ann Intern Med 173: 767-770, 2020. doi: 10.7326/M20-2665.

6) Hanson $S$ and Jones A. Is there evidence that walking groups have health benefits? A systematic review and meta-analysis. Br J Sports Med 49: 710-715, 2015. doi: 10.1136/bjsports-2014-094157.

7) Murtagh EM, Nichols L, Mohammed MA, Holder R, Nevill AM, Murphy MH. The effect of walking on risk factors for cardiovascular disease: an updated systematic review and meta-analysis of randomised control trials. Prev Med 72: 34-43, 2015. doi: 10.1016/ j.ypmed.2014.12.041.

8) Moriyama N, Urabe $Y$, Onoda S, Maeda N, Oikawa $T$. Effect of residence in temporary housing after the Great East Japan Earthquake on the physical activity and quality of life of older survivors. Disaster Med Public Health Prep 11: 701-710, 2017. doi: 10.1017/ dmp.2017.19.

9）浦辺幸夫, 森川将徳, 前田慶明 : 大学新入生の歩数調査, 靴の医学, 33: 150-154, 2019 .

10) Hurt $C P$, Lein $D H J r$, Smith $C R$, Curtis JR, Westfall AO, Cortis J, Rice C, Willig JH. Assessing a novel way to measure step count while walking using a custom mobile phone application. PLoS One 13: e0206828, 2018. doi: 10.1371/journal.pone.0206828.

11) Amagasa S, Kamada M, Sasai H, Fukushima N, Kikuchi H, Lee IM, Inoue S. How well iPhones measure steps in free-living conditions: cross-sectional validation study. JMIR Mhealth Uhealth 7: e10418, 2019. doi: 
10.2196/10418.

12) Gallè F, Sabella EA, Da Molin G, De Giglio O, Caggiano G, Di Onofrio V, Ferracuti S, Montagna MT, Liguori G, Orsi GB, Napoli C. Understanding Knowledge and Behaviors Related to CoViD-19 Epidemic in Italian Undergraduate Students: The EPICO Study. Int J Environ Res Public Health 17: 3481, 2020. doi: 10.3390/ ijerph17103481.

13) Guthold R, Stevens GA, Riley LM, Bull FC. Global trends in insufficient physical activity among adolescents: a pooled analysis of 298 population-based surveys with 1.6 million participants. Lancet Child Adolesc Health 4: 23-35, 2020. doi: 10.1016/S2352-4642 (19) 30323-2.

14) Castrogiovanni P, Trovato FM, Szychlinska MA, Nsir $\mathrm{H}$, Imbesi R, Musumeci G. The importance of physical activity in osteoporosis. From the molecular pathways to the clinical evidence. Histol Histopathol 31: 11831194, 2016. doi: 10.14670/HH-11-793.

15）厚生労働省健康局健康課. 令和元年「国民健康 - 栄 養調査」の結果, 2020. https://www.mhlw.go.jp/content/10900000/000687163.pdf（アクセス日：2020年11 月 25 日).

16）厚生労働省. 国民の健康の増進の総合的な推進を図る ための基本的な方針, 平成 24 年度版: 健康日本 $21,2013$. https://www.mhlw.go.jp/bunya/kenkou/dl/kenkounippon21_01.pdf（アクセス日：2020年 9 月 18 日).

17) Ishii $T$, Ochi $S$, Tsubokura $M$, Kato $S$, Tetsuda $T$, Kato J, Nishikawa Y, Morita T, Kami M, Iwamoto Y, Tachiya $\mathrm{H}$. Physical performance deterioration of temporary housing residents after the Great East Japan Earthquake. Prev Med Rep 2: 916-919, 2015. doi: 10.1016/ j.pmedr.2015.10.009. 